\title{
Gas-Phase Smiles Rearrangement Reactions of Deprotonated 2-(4, 6-Dimethoxypyrimidin -2-Ylsulfanyl)-N-Phenylbenzamide and Its Derivatives in Electrospray Ionization Mass Spectrometry
}

\author{
Yuping Zhou, Yuanjiang Pan, Xiaoji Cao, Jun Wu, and Kezhi Jiang \\ Department of Chemistry, Zhejiang University, Hangzhou, China
}

\begin{abstract}
The negative ions of deprotonated 2-(4, 6-dimethoxypyrimidin-2-ylsulfanyl)-N-phenylbenzamide and its derivatives are studied by electrospray ionization tandem mass spectrometry (ESI-MS/ MS). Upon collisional activation, the $[\mathrm{M}-\mathrm{H}]^{-}$ions dissociate in two competitive pathways that can be considered as the gas-phase Smiles rearrangement reactions, giving rise to the characteristic fragment ions $\left[\mathrm{M}-\mathrm{H}-\mathrm{C}_{7} \mathrm{H}_{4} \mathrm{OS}\right]^{-}$and $\left[\mathrm{M}-\mathrm{H}-\mathrm{C}_{13} \mathrm{H}_{8} \mathrm{NSR}\right]^{-}(\mathrm{R}=$ substituent). Theoretical computations were invoked to shed light on the reaction mechanisms of the representative Compound 1 by the semiempirical PM3 method. These theoretical calculations show that the formation of $\left[\mathrm{M}-\mathrm{H}-\mathrm{C}_{13} \mathrm{H}_{8} \mathrm{NSR}\right]^{-}(\mathrm{R}=\mathrm{H}$ for Compound 1 ) is more favorable. Furthermore, it is found that the intensities of the two product ions are strongly influenced by the position and the nature of the substituents. For the para-substituted compounds, the $\ln \left[\left(\mathrm{M}-\mathrm{H}-\mathrm{C}_{7} \mathrm{H}_{4} \mathrm{OS}^{-}\right) /\left(\mathrm{M}-\mathrm{H}-\mathrm{C}_{13} \mathrm{H}_{8} \mathrm{NSR}^{-}\right)\right]$values are well correlated with the $\sigma_{\mathrm{p}}^{-}$substituent constants. In addition, the dependence of the intensity ratios of these two ions, $\ln \left[\left(\mathrm{M}-\mathrm{H}-\mathrm{C}_{7} \mathrm{H}_{4} \mathrm{OS}^{-}\right) /\left(\mathrm{M}-\mathrm{H}-\mathrm{C}_{13} \mathrm{H}_{8} \mathrm{NSR}^{-}\right)\right]\left(\mathrm{R}=\mathrm{CH}_{3}\right)$, on the collision energy can be used to distinguish the positional isomers. (J Am Soc Mass Spectrom 2007, 18, 1813-1820) (c) 2007 American Society for Mass Spectrometry
\end{abstract}

$\mathrm{T}$ he 4, 6-dimethoxypyrimidine derivatives are widely used as pesticides. For example, O-pyrimidinylsalicylates show very strong herbicidal activity under pre- and postemergent treatment conditions against various grasses and broadleaf weeds [1, 2]. Also, the 2-(4,6-dimethoxypyrimidin-2-ylthio)benzoic acid derivatives are found to exhibit herbicidal activities against grasses and broadleaf weeds over a wide range of growth stages $[3,4]$. Therefore, a series of 2-(4,6-dimethoxypyrimidin-2-ylsulfanyl)-N-phenylbenzamide derivatives was synthesized in our laboratory [5] as precursors of pesticides. Studies on the mass spectrometric behavior of these compounds should provide additional information about the chemical transformation in the solution phase, which might be helpful in the understanding of the metabolizable behavior of these compounds [6-9].

Previous studies $[10,11]$ showed that the major fragmentation of protonated amides observed in mass spectrometry was the cleavage of the amide bond. However, deprotonated molecules of the amide compounds we were interested in may dissociate differ-

Address reprint requests to Dr. Yuanjiang Pan and Prof. Jun $\mathrm{Wu}$, Department of Chemistry, Zhejiang University, Hangzhou 310027, China. E-mail: panyuanjiang@zju.edu.cn,wujunwjwj@sohu.com ently. As a matter of fact, it has already been reported [9] that upon collisional activation, certain deprotonated amides underwent a skeletal rearrangement before the fragmentation. A gas-phase type Smiles rearrangement mechanism was proposed to explain this rearrangement. The Smiles rearrangement in the solution phase has been well documented as an aromatic ipso nucleophilic substitution reaction $[12,13]$ as summarized in Scheme 1. The reaction could be simulated by mass spectrometry in the negative-ion mode, since the Smiles rearrangement reaction is known mainly through a base-catalyzed rearrangement mechanism [9]. The nucleophilic attack normally requires an electron-withdrawing group (e.g., nitro, sulfonyl, or halogen) either at the ortho or para position on the aromatic ring. However, gas-phase studies on $\mathrm{PhO}\left(\mathrm{CH}_{2}\right)_{n} \mathrm{O}^{-}(n$ $=2-4$ ) carried out by Eichinger et al. [14-16] suggested that the Smiles rearrangement can be initiated upon collisional activation without any electron-withdrawing substituents. More recently, similar rearrangement reactions were also reported by Guo et al. in studies on 2-pyrimidinyloxy-N-aryl-benzylamine derivatives [9] and by Wang et al. in collision-induced dissociation studies on phenoxy-N-phenylacetamide derivatives [17].

The purpose of the present study was to elucidate the fragmentation mechanism of 2-(4,6-dimethoxypyrimidin- 


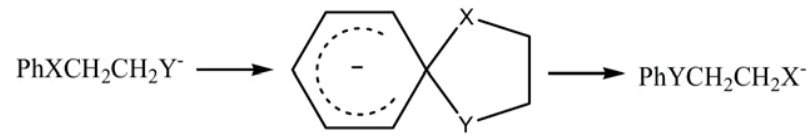

Scheme 1. Classical Smiles rearrangement.

2-ylsulfanyl)-N-phenylbenzamide and its derivatives by ESI negative ion mass spectrometry. The elemental compositions of all the ions were confirmed by highresolution Fourier transform ion cyclotron resonance ESI mass spectrometry (FTICR-ESI-MS/MS). In addition, some theoretical computations were carried out to support the proposed mechanisms of the gas-phase reactions. Interestingly, two competitive Smiles rearrangement reactions were observed. The relationship between the relative abundances of the two product ions resulting from these two competitive Smiles rearrangement reactions and the nature of the substituents were investigated.

The information in a mass spectrum obtained at one single collision energy is limited but can be significantly enhanced by examining changes in the profile with ramping collision energies, or the so-called energyresolved mass spectrometry (ERMS). A plot of relative intensity of selected fragment ions versus collision energy leads to the generation of breakdown curves [18].Che@valuation@f@reakdown@urves@an@rovide information on fragmentation mechanisms such as distinguishing between competitive and consecutive fragmentation pathways, the stability of product ions, and theđidentification@ofđisomers@and@automers@19,C20]. Here we used the plots of intensity ratios of the two product ions, instead of the relative abundance of the respective ions, versus the collision energy to differentiate the three methyl-substituted positional isomers. It was demonstrated that the positional isomers of the studied compounds could be distinguished by this method.

\section{Experimental}

All compounds used in this study were synthesized

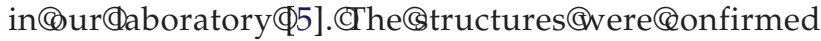
using ${ }^{1} \mathrm{H}$ NMR, ${ }^{13} \mathrm{C}$ NMR, IR, and high-resolution mass spectrometry after purification of the synthesized products.

The samples were first analyzed on a Bruker Esquire $3000^{\text {plus }}$ mass spectrometer; Bruker, Billerica, MA equipped with an ESI ion source in the negative ionization mode, with data acquisition using the Esquire 5.0 software. The compounds were dissolved in methanol. The solutions were infused into the source chamber at a flow rate of $2 \mu \mathrm{L} \mathrm{min}{ }^{-1}$ and nitrogen was used as the nebulizing gas at a pressure of $15 \mathrm{psi}$, while the drying gas was at a flow rate of $5 \mathrm{~L} \mathrm{~min}^{-1}$. The capillary voltage was set at $4000 \mathrm{~V}$, and the ion source temperature was at $250^{\circ} \mathrm{C}$. The collision-induced dissociation (CID) mass spectra were obtained with helium as the collision gas after isolation of the precursor ions, and the collision energy was set at 0.3 to $0.8 \mathrm{~V}$ to give suitable energy for the dissociation of all samples.

All accurate masses were measured on an Apex III (7.0 tesla) FTICR mass spectrometer (Bruker). Sodium trifluoroacetate was selected as an external calibration compound for negative ion electrospray ionization mass spectrometry in the mass range 200 to $900 \mathrm{Da}$. The solutions were infused from the ESI source at $3 \mu \mathrm{L}$ $\mathrm{min}^{-1}$ with the following parameters applied: capillary, $3946 \mathrm{~V}$; end plate, $3767 \mathrm{~V}$; skimmer 1, -15.47 V; skimmer 2, $-9.42 \mathrm{~V}$; offset, $-1.01 \mathrm{~V}$; RF amplitude, $500 \mathrm{~Hz}$; drying gas temperature, $150{ }^{\circ} \mathrm{C}$. Nitrogen was used as the nebulizing and drying gases, and argon was used as the collision gas. MS/MS parameters: correlation sweep pulse length, $2000 \mu$ s; correlation sweep attenuation, 18 $\mathrm{dB}$; ejection safety belt, $1000 \mathrm{~Hz}$; ion activation pulse length, 250,000 $\mu \mathrm{s}$; ion activation attenuation, between 40 and $50 \mathrm{~dB}$; frequency offset from activation mass, 600 $\mathrm{Hz}$; and user delay length, $3 \mathrm{~s}$.

All theoretical calculations were carried out by the semiempirical PM3 method with the Gaussian 03 program@21].CSemiempirical@molecular@orbital@methods based on the neglect of diatomic differential overlap (NDDO) approximation continue to find widespread use in variety of applications. PM3, for example, is widely used for relative large systems. When confined by some parameters that come from experiment, PM3 can get very good calculation results. Furthermore, when compared with the DFT and ab initial method, semiempirical methods have speed as their main advantage. The candidate transition-state structures and the key structures on the potential energy surface were optimized with calculating force constants. No symmetry constrains have been imposed in the optimizations. All optimized structures were subjected to vibrational frequency analysis for zero-point energy (ZPE) correction, and the reaction pathways were traced forward and backward by intrinsic reaction coordinates (IRC) method. Sum of electronic and thermal energies (in $\mathrm{kcal} / \mathrm{mol}$ ) of the optimized structures were calculated. The semiempirical PM3 optimized structures were shown by Gauss View version 3.09 software to give higher quality images of these structures.

\section{Results and Discussion}

The structures of 2-(4,6-dimethoxypyrimidin-2ylsulfanyl)-N-phenylbenzamide (Compound 1), its derivatives (Compounds 2-11), and N-cyclohexyl-2(4,6-dimethoxypyrimidin-2-ylsulfanyl)benzamide (Compound@2)@re@hown@indable@.థr@ill@he@ompounds, the deprotonated molecular ions were produced under negative ion ESI conditions. In the MS/MS experiments, the mass spectra were obtained under the same conditions as described in the experimental section. Generally, Compounds 1-11 gave similar fragmentation in the negativeion ESI-MS/MS experiments, whereas the position and the nature of the substituents merely affected the relative 
Table 1. Structures of title compounds 1-12

\begin{tabular}{|c|c|c|}
\hline Comp & \multicolumn{2}{|c|}{ Compound 12 M.W. 373} \\
\hline Compounds & MW & $\mathrm{R}$ \\
\hline 1 & 367 & $\mathrm{H}$ \\
\hline 2 & 381 & $\mathrm{o}-\mathrm{CH}_{3}$ \\
\hline 3 & 381 & $m-\mathrm{CH}_{3}$ \\
\hline 4 & 381 & $p-\mathrm{CH}_{3}$ \\
\hline 5 & 412 & $p-\mathrm{NO}_{2}$ \\
\hline 6 & 397 & $p-\mathrm{OCH}_{3}$ \\
\hline 7 & 385 & $p-\mathrm{F}$ \\
\hline 8 & 401 & $p-\mathrm{Cl}$ \\
\hline 9 & 445 & $p-\mathrm{Br}$ \\
\hline 10 & 435 & $p-\mathrm{CF}_{3}$ \\
\hline 11 & 410 & $p-\mathrm{N}\left(\mathrm{CH}_{3}\right)_{2}$ \\
\hline
\end{tabular}

abundances of the fragment ions. The representative Compound 1, 2-(4, 6-dimethoxypyrimidin-2-ylsulfanyl)$\mathrm{N}$-phenylbenzamide, was selected as a model to explain the possible dissociation pathways. The full scan ESI mass spectrum of Compound 1 showed an abundant deprotonated molecule ion at $\mathrm{m} / \mathrm{z}$ 366. Upon collisional ac-
Table 2. Main product ions observed in the ESI-MS/MS spectra of the deprotonated compounds

\begin{tabular}{|c|c|c|}
\hline Compounds & $\begin{array}{l}\text { Precursor ions } \\
\qquad[\mathrm{M}-\mathrm{H}]^{-}\end{array}$ & $\begin{array}{l}\text { Relative abundances of } \\
\text { product ions } \mathrm{m} / \mathrm{z}(\%)\end{array}$ \\
\hline & $b$ & $d$ \\
\hline 1 & 366 & $230(100), 155(46)$ \\
\hline 2 & 380 & $244(100), 155(57)$ \\
\hline 3 & 380 & $244(100), 155(58)$ \\
\hline 4 & 380 & $244(100), 155(69)$ \\
\hline 5 & 411 & $275(100), 155(0.01)$ \\
\hline 6 & 396 & $260(100), 155(78)$ \\
\hline 7 & 384 & $248(100), 155(24)$ \\
\hline \multirow[t]{2}{*}{8} & 400 & $264(100), 155(5)$ \\
\hline & 402 & $266(100), 155(6)$ \\
\hline \multirow[t]{2}{*}{9} & 444 & $308(99), 155(3)$ \\
\hline & 446 & $310(100), 155(3)$ \\
\hline 10 & 434 & $298(100), 155(0.4)$ \\
\hline 11 & 409 & $273(78), 155(88)$ \\
\hline 12 & 372 & $236(0.7), 155(100)$ \\
\hline
\end{tabular}

tivation, it yielded two major product ions at $\mathrm{m} / \mathrm{z} 230$ and@55,@s@hown@inథigure@a.đn@addition, @ompound 12, N-cyclohexyl-2-(4,6-dimethoxypyrimidin-2-ylsulfanyl) benzamide, was selected as a contrast. The major product ions with their relative abundances (RA) from the precur-

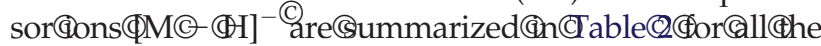
compounds studied. Although the $m / z$ values were ap-

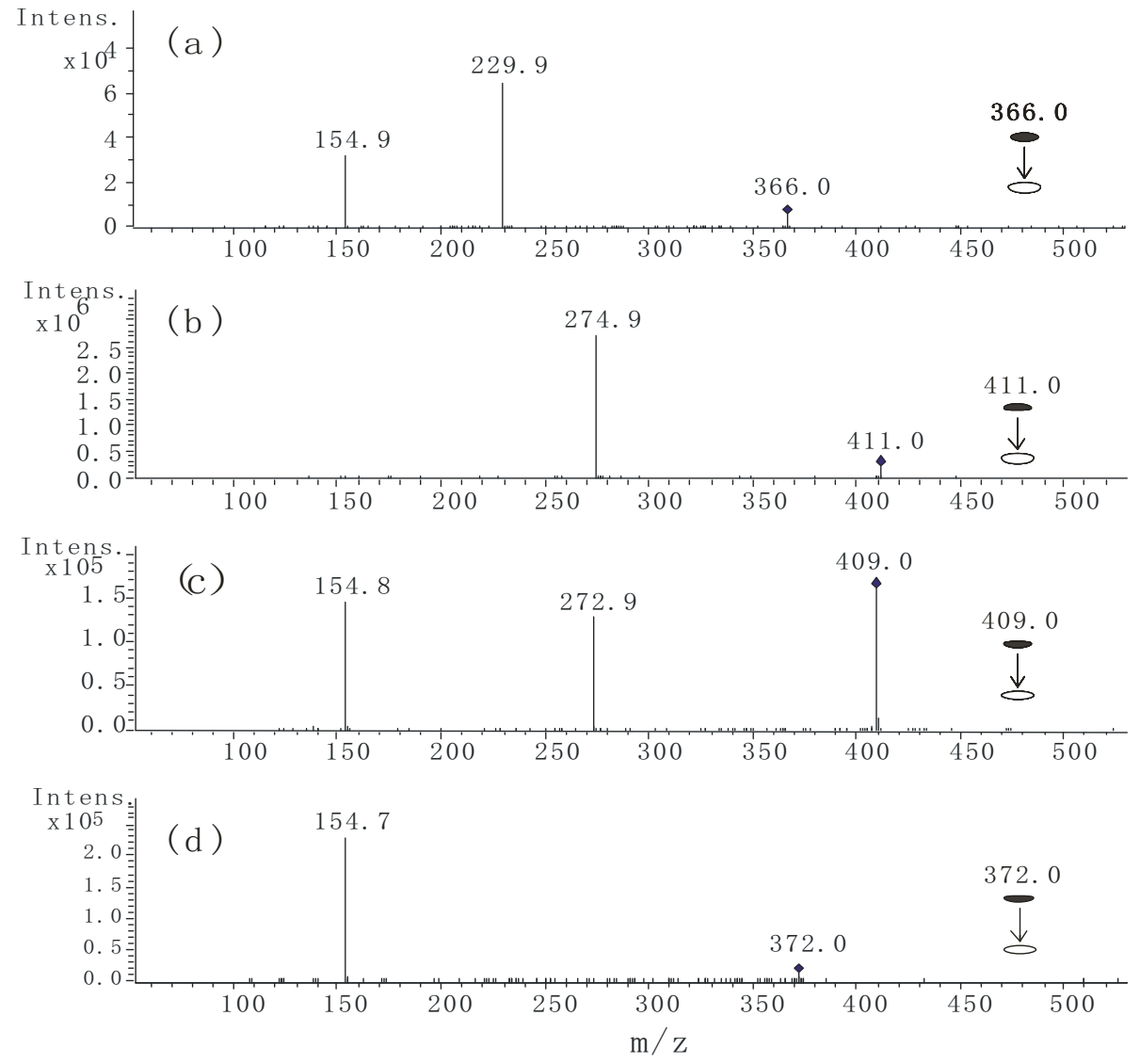

Figure 1. The MS/MS spectra of $[\mathrm{M}-\mathrm{H}]^{-}$ions of (a) Compound 1, (b) Compound 5, (c) Compound 11, and (d) Compound 12 in the negative-ion ESI mode. 


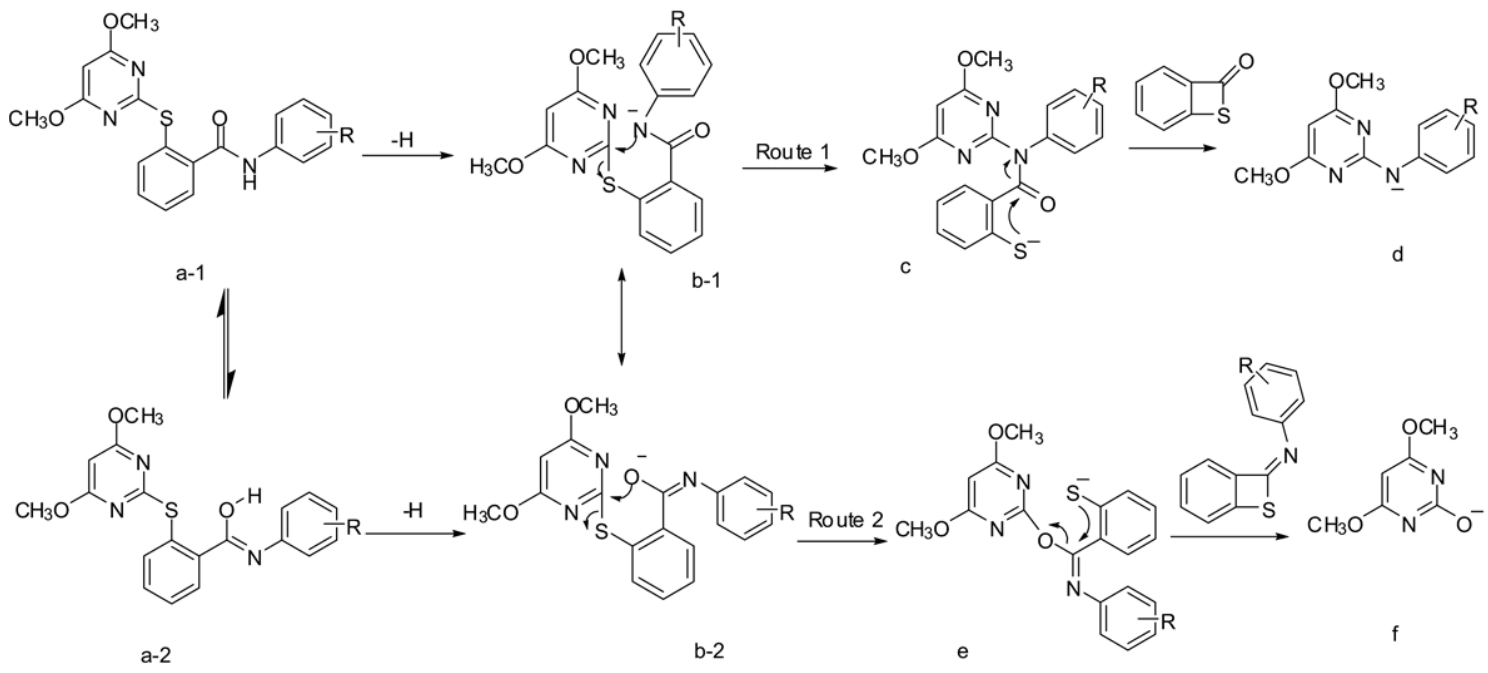

Scheme 2. Proposed MS/MS fragmentation mechanism of deprotonated Compounds 1-11.

proximately in the range 350 to 450 , there were only a few product ions observed, indicating dominant fragmentation pathways. The formation of these fragment ions can be rationalized by a reaction mechanism as described in Schemes 2, 3, and 4 . The ions were labeled as $\mathbf{a}-\mathbf{f}$, and the details of the pathways are described in the following section. In fact, the fragmentation in the gas phase was equivalent to the Smiles rearrangement in the solution phaseథ11,®2].

To confirm the proposed structures, the exact mass measurements of the product ions were carried out by high-resolution FTICR-MS/MS. The most probable elemental compositions of these ions were obtained with a high degree of confidence. The errors between the observed masses and calculated values are within \pm 1.5 ppm, with maximum error of $1.3 \mathrm{ppm}$ and average error of $0.3 \mathrm{ppm}$, indicating very good mass accuracy and confirming the compositions of the ions.

Figuređa@hows@he@SI-MS/MS@pectrum@f@ompound 1, as an example of the characteristic fragmentation observed for this series of compounds. The formation process of the ions at $\mathrm{m} / \mathrm{z} 230$ and 155 from deprotonated 1 cannot be rationalized without invoking skeletal rearrangements before the fragmentation. Two competitive gas-phase Smiles rearrangement mechanisms were proposed to explain the formation of the ions at $\mathrm{m} / \mathrm{z} 230$ and 155, corresponding to neutral losses of 136 and $211 \mathrm{Da}$, respectively. The mechanism is shown in Scheme 2.
The amide group of Compound 1 can isomerizes to the enol form. Hence there were two tautomers, $\mathrm{M}_{\text {keto }}(\mathrm{a}-1)$ and $\mathrm{M}_{\text {enol }}(\mathrm{a}-2)$, both of which could be deprotonated with ESI@n@he@egative@on@nodeథ22].@After@oss@f@he@abile proton, the $[\mathrm{M}-\mathrm{H}]^{-}$ions can form many conformational isomers, as the negative charge can distribute to the atoms with different proportions. Among these, the lone electron pair localize either at the nitrogen atom or at the oxygen atom (see structures b-1 and b-2) will possess relative higher proportion. Two competitive Smiles rearrangement reactions, Route 1 and Route 2, occurred because of the presence of two nucleophilic centers, as shown in Scheme 2. For Route 1, the nitrogen atom with the lone electron pair attacked the electrophilic center while for Route 2 the oxygen atom acted as a nucleophile. The final ions at $m / z 230$ and 155 were gained via the neutral losses of 136 mass units of $2 \mathrm{H}$-benzo[b]thiet-2-one and 211 mass units of $(\mathrm{Z})-\mathrm{N}$ (2H-benzo[b]thiet-2-ylidene)benzenamine, respectively.

Theoretical computations were invoked to support the proposed mechanisms and show the possible existence of some transition states@and@intermediates@in-

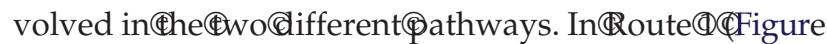
2), (the nitrogen anion first attacked the 2-position carbon of pyrimidine, involving cleavage of the $\mathrm{C}-\mathrm{S}$ bond to form $c$ ion through transition-state 1 (TS1). Then the sulfur anion attacks the carbonyl with the cleavage of the $\mathrm{C}-\mathrm{N}$ bond to form the neutral molecular RN1 and $\mathrm{d}$ ion via transition-state 2 (TS2). The semiempirical PM3

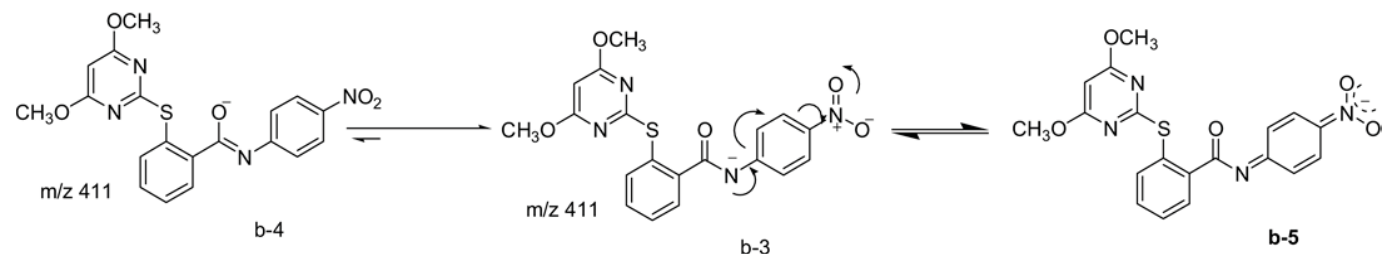

Scheme 3. Proposed resonance transformation of deprotonated Compound 5. 
<smiles>CC#CC1CCC(N=C(O)c2ccccc2Sc2nc(OC)cc(OC)n2)CC1</smiles>

Scheme 4. Proposed resonance transformation of deprotonated Compound 12.

optimized structures, the lengths of important bonds (in $\AA$ ), the distances between approaching atoms (shown in dashed in $\AA$ ) and the calculated heats of formation of species involved in this nitrogen attack Smiles rearrangement@eaction@re@eported@n@igure@.

RouteC2@Figure@B)@s@ilso@ CSmiles@rearrangement mechanism, whereas the oxygen anion acted as nucleophile to attack the 2-position carbon of the pyrimidine. The mid-process seems to be quite alike. The final product ion $\mathrm{f}$ was obtained via the neutral loss of RN2 through transition-state 4 (TS4). The semiempirical PM3 optimized structures, the lengths of important bonds (in $\AA$ ), the distances between approaching atoms (shown in dashed in $\AA$ ) and the calculated heats of formation of species involved in this oxygen attack Smiles@earrangement@eaction@re@eported@i ॠigure@.

A schematic potential energy surface for the two proposed@nechanisms@s@iven@n@igure@.đAnalysis@f Figure@4ndicates@hat@he@ctivation@barriers@or@he skeletal rearrangement for both Routes (from b- 1 to $c$ in Route 1; and from b-2 to e in Route 2) are substantially lower than those of the dissociation steps (from $\mathrm{c}$ to $\mathrm{d}$ in Route 1; and from e to $\mathrm{f}$ in Route 2). The skeletal rearrangement steps are reversible and the relative populations of intermediate species $\mathrm{c}$ and e are therefore sensitive to the relative energies of $\mathrm{c}$ and e. From the optimized structures, it is not difficult to tell that the structure of intermediate $\mathrm{c}$ is much more stable than e. The two structures are quite similar except for the difference in the mid-frame. The imidate in structure e is unstable because of the presence of the electron withdrawing effect of the 4,6-dimethoxy-2-methylpyrimidine. Compared with $\mathrm{e}$, the structure of $\mathrm{c}$ with the amide group in the middle is far more stable. Hence, the relative abundance of intermediate species $\mathrm{c}$ is higher than that of@he@.Cstudy@figure@ @hows@hat@he rate determining steps for both Smiles rearrangement reactions are the actual dissociation steps. Since the rate determining steps are the irreversible dissociation steps, they are kinetically controlled. The difference in their rate of reactions depends on their difference in overall activation barriers, which means the product ion $\mathrm{d}$, favored as the overall activation of Route $1(22.0 \mathrm{kcal} / \mathrm{mol})$, is less than that of Route $2(31.1 \mathrm{kcal} / \mathrm{mol})$. In sum, these calculation results indicate that the nitrogen attack Smiles rearrangement reaction is more favorable than the oxygen attack mechanism, which can explain the

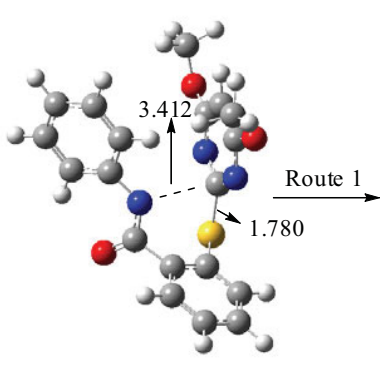

$[\mathbf{M}-\mathrm{H}]^{-} \quad$ b-1

$170.7 \mathrm{Kcal} / \mathrm{mol}$

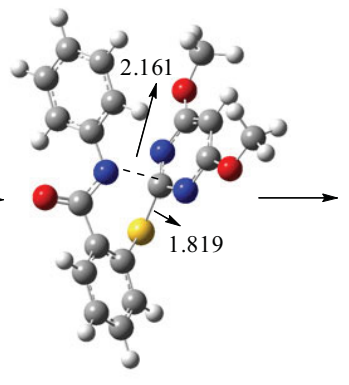

TS1

$182.1 \mathrm{Kcal} / \mathrm{mol}$

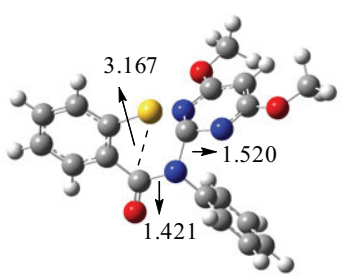

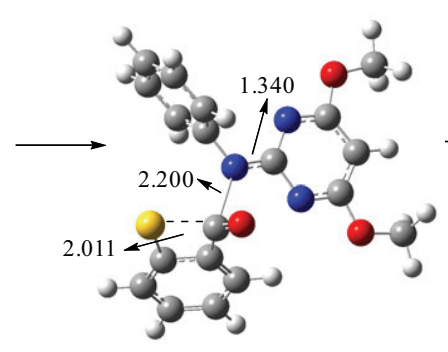

TS2

$192.7 \mathrm{Kcal} / \mathrm{mol}$

RN1

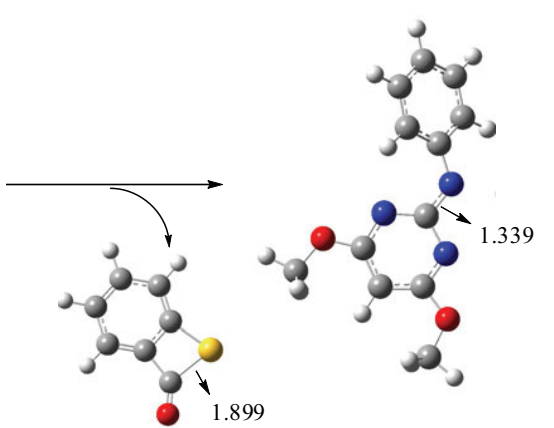

d

$175.5 \mathrm{Kcal} / \mathrm{mol}$

Figure 2. PM3 optimized structures of the species in the nitrogen attack Smiles rearrangement of deprotonated Compound 1 via transition-state (TS1) and the neutron loss of RN1 via transition-state (TS2). Heats of formation are given as $\mathrm{kcal} / \mathrm{mol}$ and the length of the chemical bonds are given in $\AA$. 


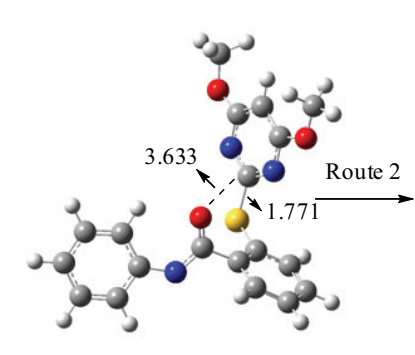

$[\mathrm{M}-\mathrm{H}]^{-} \quad$ b-2

$172.9 \mathrm{Kcal} / \mathrm{mol}$

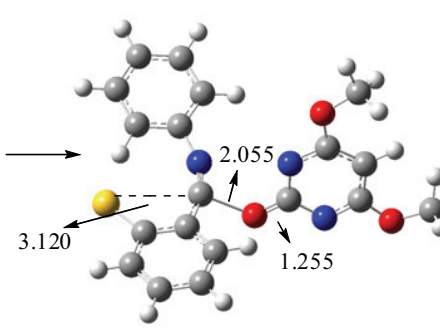

TS4

$201.8 \mathrm{Kcal} / \mathrm{mol}$

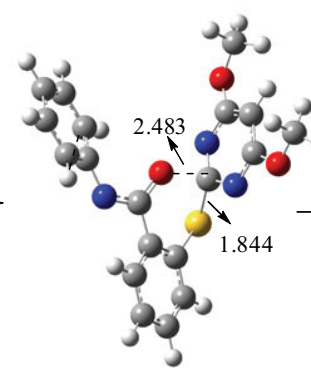

TS3

$186.2 \mathrm{Kcal} / \mathrm{mol}$

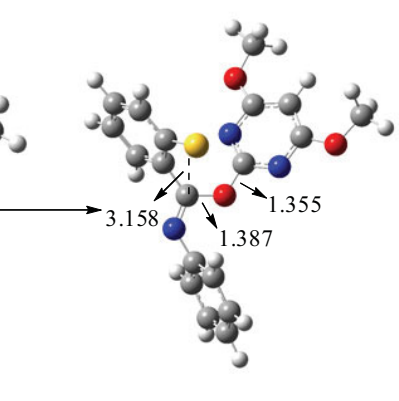

e

$184.8 \mathrm{Kcal} / \mathrm{mol}$

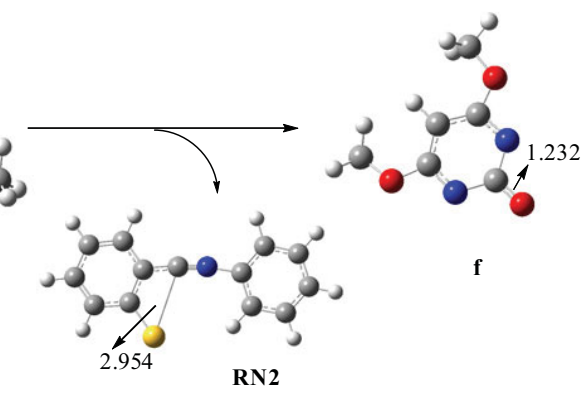

$190.8 \mathrm{Kcal} / \mathrm{mol}$

Figure 3. PM3 optimized structures of the species in the oxygen attack Smiles rearrangement of deprotonated Compound 1 via transition-state (TS3) and the neutron loss of RN2 via transition-state (TS4). Heats of formation are given as $\mathrm{kcal} / \mathrm{mol}$ and the length of the chemical bonds are given in $\AA$.

reason why the relative abundance of the ion at $m / z 230$ is higher than that of the ion at $\mathrm{m} / \mathrm{z} 155$.

The relative abundance of the product ions is affected both by the position and the nature of the substituents, as the overall activation barriers are related to the substituents to some extent. The nature of the substituents will be discussed according to the electronic effect with the substituents located at the para position. In the rate determining steps, a negative charge is developing at the nitrogen atom connecting the substituted phenyl ring in TS2, while the negative charge is developing at the remote oxygen in TS4. When the substituent is an electron withdrawing group, such as $\mathrm{CF}_{3}, \mathrm{NO}_{2}$, the overall activation barrier of TS2 is reduced since the negative charge at the nitrogen atom can be largely stabilized by the substituted phenyl ring, leading to much more favor of the Route 1 . At the same time, the overall activation barrier of Route 2 is almost constant, as the substituent has hardly any effect on the remote negative charged oxygen atom. Hence, the product ion $\mathrm{d}$ is more favored when the substituent is an electron withdrawing group. Besides, in the skeletal rearrangement steps, the structure b- 1 is highly favored because the lone electron pair at nitrogen atom could be largely delocalized to the phenyl ring, leading to an additional@stable@resonance@tructure@b-5@23], Cas@described in Scheme 3. It is proposed that for these compounds, the isomerization of ion $\mathbf{b}-\mathbf{3}$ to $\mathbf{b}-\mathbf{4}$ is difficult due to the presence of the strong electronwithdrawing group. Considering the above two factors, especially the decisive factor of the overall activation barriers of TS2 and TS4, the Route 1 is more favored, resulting in higher relative abundance of product ion $\mathrm{d}$. Therefore, for Compound 5, Route 2 could hardly occur,@nd@he@on@t@/z 275@as@ominant $₫$ see@igure 1b).Фor@he@alogen@ubstituted@ompounds, such as F, $\mathrm{Cl}, \mathrm{Br}$, the overall trend is the same as the above discussed compounds, which means the relative abundance of the $d$ ion is much higher than that of the $\mathrm{f}$ ion. In contrast, when the substituent is electron-donating groups, such as $-\mathrm{N}\left(\mathrm{CH}_{3}\right)_{2}$, the overall activation barrier of TS2 is fortified by the destabilizing of the negative

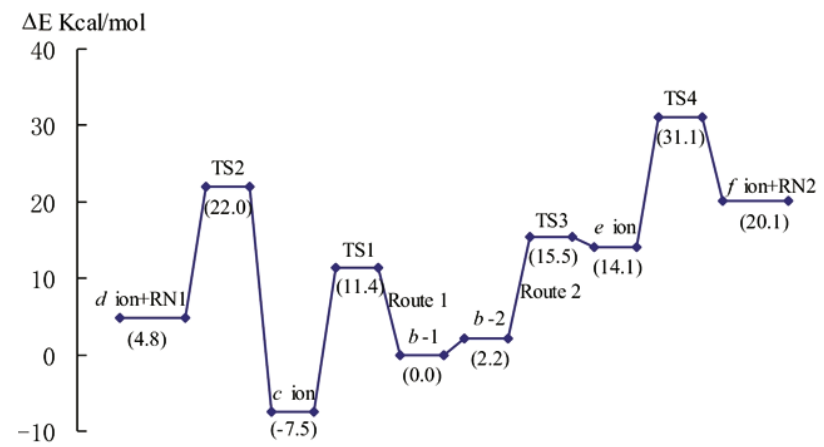

Figure 4. Schematic of potential energy surface (relative energies are given in $\mathrm{kcal} / \mathrm{mol}$ ) for the two proposed fragmentation pathways of deprotonated Compound 1, calculated by semiempirical PM3. Route 1 is the nitrogen attack Smiles rearrangement; route 2 is the oxygen attack Smiles rearrangement. 
charged nitrogen atom. Accordingly, the oxygen attack Smiles rearrangement will be relatively favored (see Figure@c).

To prove the mechanism proposed above, we also synthesized N-cyclohexyl-2-(4,6-dimethoxypyrimidin2-ylsulfanyl)benzamide, namely, Compound 12. The CID mass spectrum of the $[\mathrm{M}-\mathrm{H}]^{-}$ion $(\mathrm{m} / \mathrm{z} 372)$ is shown@in@igure@d.@learly, (he@elative@bundance@f the $\left[\mathrm{M}-\mathrm{H}-\mathrm{C}_{7} \mathrm{H}_{4} \mathrm{OS}\right]^{-}$ion was only $0.7 \%$, and that of the ion at $m / z 155$ was $100 \%$, the base peak. This is because the nitrogen atom linked directly with a cyclohexane, which itself is an electron-releasing group, destabilizing the TS2 to a great extent. Thereby, the overall activation barrier of Route 1 is much larger than that of Route 2. Moreover, the cyclohexyl group destabilized the $\mathbf{b}-\mathbf{1 2}$ ion with the formal negative charge on the nitrogen.

To study the influence of the substituents to these two competitive Smiles rearrangement reactions systematically, the spectra of a series compounds with different substituents at para position were measured (the relative abundance of the ions was shown in Table(2).CThe@fragment@mechanism@could@be@further explored by studying the substituent effects on the distribution of the product ions. A plot of the intensity ratios of these two ions, $\ln \left[\left(\mathrm{M}-\mathrm{H}-\mathrm{C}_{7} \mathrm{H}_{4} \mathrm{OS}^{-}\right) /(\mathrm{M}-\right.$ $\left.\left.\mathrm{H}-\mathrm{C}_{13} \mathrm{H}_{8} \mathrm{NSR}^{-}\right)\right]$versus the substituent constants, $\sigma_{\mathrm{p}}^{-}$, was@btained@s@hown@inథigure(\$).(Here@he@ubstituent constant, $\sigma_{\mathrm{p}}^{-}$, was used since the lone electron pair on the $\mathrm{O}^{-}$or $\mathrm{N}^{-}$could be delocalized into substituents [24].Фheథrend@s@lear.(An@lectron-withdrawing@roup retarded the oxygen atom attack Smiles rearrangement, whereas an electron-donating substituents expedited this rearrangement. In general, compared with Compound $1(\mathrm{R}=\mathrm{H})$, all electron-withdrawing groups $\left(\sigma_{\mathrm{p}}^{-}>0\right)$ favor the formation of the $\left[\mathrm{M}-\mathrm{H}-\mathrm{C}_{7} \mathrm{H}_{4} \mathrm{OS}\right]^{-}$ ion, and electron-donating groups $\left(\sigma_{\mathrm{p}}^{-}<0\right)$ favor the other channel to form $\left[\mathrm{M}-\mathrm{H}-\mathrm{C}_{13} \mathrm{H}_{8} \mathrm{NSR}\right]^{-}$ion

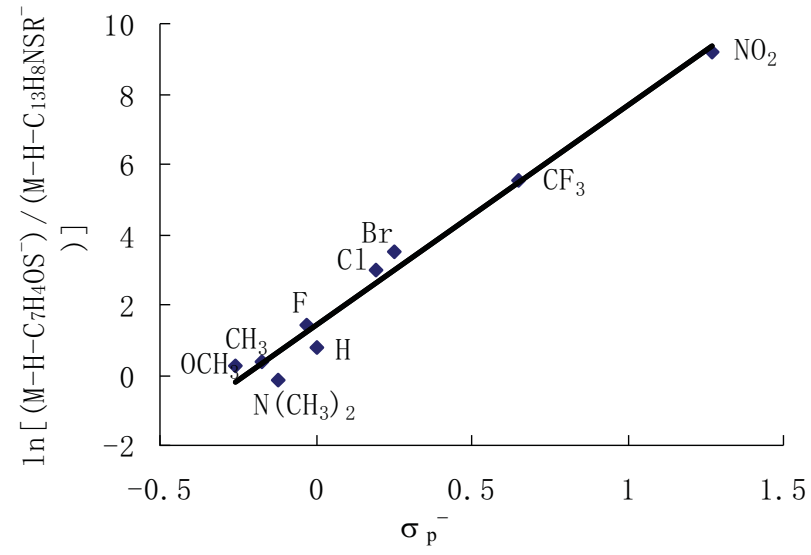

Figure 5. Plot of $\ln \left[\left(\mathrm{M}-\mathrm{H}-\mathrm{C}_{7} \mathrm{H}_{4} \mathrm{OS}^{-}\right) /\left(\mathrm{M}-\mathrm{H}-\mathrm{C}_{13} \mathrm{H}_{8} \mathrm{NSR}^{-}\right)\right]$ versus the $\sigma_{\mathrm{p}}^{-}$substituent constants for the collision-induced fragmentation of the $[\mathrm{M}-\mathrm{H}]^{-}$ions of 2-(4,6-dimethoxypyrimidin-2-ylsulfanyl)-N-phenylbenzamide substituted at the para position. Collision energy $0.54 \mathrm{~V}$ (helium).

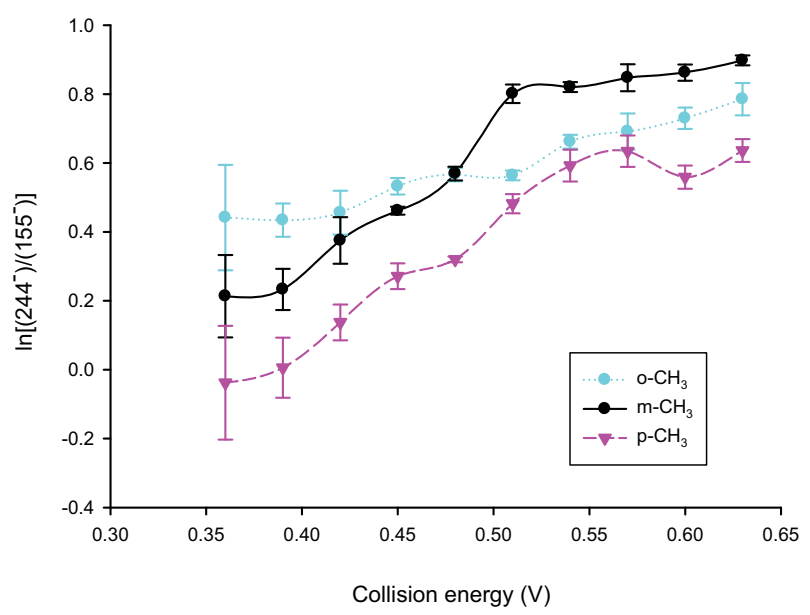

Figure 6. Plot of $\ln \left[\left(244^{-}\right) /\left(155^{-}\right)\right]$versus the collision energy for deprotonated Compounds $2(\mathrm{R}=\mathrm{o}-\mathrm{CH} 3), 3(\mathrm{R}=\mathrm{m}-\mathrm{CH} 3)$ and 4 $(\mathrm{R}=\mathrm{p}-\mathrm{CH} 3)$.

instead. For example, Compound $1(\mathrm{R}=\mathrm{H})$ yielded $\left[\mathrm{M}-\mathrm{H}-\mathrm{C}_{7} \mathrm{H}_{4} \mathrm{OS}\right]^{-}$ion and $\left[\mathrm{M}-\mathrm{H}-\mathrm{C}_{13} \mathrm{H}_{8} \mathrm{NSR}\right]^{-}$ ion in the ratio 100:46; Compound $5\left(\mathrm{R}=\mathrm{NO}_{2}\right)$ yielded these two ions in the ratio 100:0.01; in the case of Compound $11\left(\mathrm{R}=\mathrm{N}\left(\mathrm{CH}_{3}\right)_{2}\right)$, the ratio of $m / z 273$ to 155 is $78: 88$.

Three methyl-substituted isomers were selected to study the positional factor. However the spectrometric information in a MS/MS spectrum obtained at one single collision energy is limited and can be significantly enhanced by acquiring spectra at increasing greater collision energies. Therefore, the plots of intensity ratios of these two ions, $\ln \left[\left(244^{-}\right) /\left(155^{-}\right)\right]$, instead of relative intensity, versus the collision energy, were obtained. The intensity ratios of $\ln \left[\left(\mathrm{M}-\mathrm{H}-\mathrm{C}_{7} \mathrm{H}_{4} \mathrm{OS}^{-}\right) /\right.$ $\left(\mathrm{M}-\mathrm{H}-\mathrm{C}_{13} \mathrm{H}_{8} \mathrm{NSR}^{-}\right)$] varied correspondingly with substituent constant, $\sigma^{-}$, as discussed above. Therefore, these values are plotted on y-axis. The three positional isomers are hence easily distinguished since the electronic effect of the substituent at the ortho, meta, and para positions is different.

Figure@@hows@how@he@ntensity@atios@f@he@wo ions, $\ln \left[\left(\mathrm{M}-\mathrm{H}-\mathrm{C}_{7} \mathrm{H}_{4} \mathrm{OS}^{-}\right) /\left(\mathrm{M}-\mathrm{H}-\mathrm{C}_{14} \mathrm{H}_{11} \mathrm{NS}^{-}\right)\right]$, obtained by CID of $[\mathrm{M}-\mathrm{H}]^{-}$from Compounds $2(\mathrm{R}=$ $\mathrm{o}-\mathrm{CH} 3), 3(\mathrm{R}=\mathrm{m}-\mathrm{CH} 3)$ and $4(\mathrm{R}=\mathrm{p}-\mathrm{CH} 3)$ varied as the collision energy varied from 0.36 to $0.63 \mathrm{~V}$. The intensity ratios of the two ions of Compounds 2, 3, and 4 are drastically different, which can be explained by the influence of different substituted positions. The methyl group is an inductively electron donating-group, which favors relatively the formation of $[\mathrm{M}-\mathrm{H}-$ $\left.\mathrm{C}_{14} \mathrm{H}_{11} \mathrm{NS}\right]^{-}$compared with the non-substituent Compound $1(\mathrm{R}=\mathrm{H})$. The electron-releasing effect of methyl group is a bit stronger at the para and ortho than at the meta position. Hence, Compound 4 has a smaller value of $\ln \left[\left(244^{-}\right) /\left(155^{-}\right)\right]$than that of Compound 3 at the same collision energy, which is consistent with the experiment result. However, Compound 2, whose plot of $\ln \left[\left(244^{-}\right) /\left(155^{-}\right)\right]$versus the collision energy intersect 
Compound 3 around $0.48 \mathrm{~V}$ could not be simply compared with that of Compounds 3 and 4 , as some other factors, for instance the steric effect of $o$-substituent, should also be considered. The error bars shown in the figure also prove that these three isomers can be differentiated. When the collision energy is $0.36 \mathrm{~V}$, the relative abundance of the two product ions at $\mathrm{m} / \mathrm{z} 244$ and 155 are quite small, which results in the biggest error, and the three points at $0.36 \mathrm{~V}$ overlap partially with each other. However, with the increase of the collision energy, the three curves can be distinguished easily. For example, although o- $\mathrm{CH} 3$ and $\mathrm{m}-\mathrm{CH} 3$ had superposition at 0.42 and $0.48 \mathrm{~V}$, they detached each other at other points. Therefore, it was possible to identify 2-(4,6-dimethoxypyrimidin-2-ylsulfanyl)-Nphenylbenzamide isomers from the above method by comparing the values of $\ln \left[\left(\mathrm{M}-\mathrm{H}-\mathrm{C}_{7} \mathrm{H}_{4} \mathrm{OS}^{-}\right)\right.$/ $\left.\left(\mathrm{M}-\mathrm{H}-\mathrm{C}_{14} \mathrm{H}_{11} \mathrm{NS}^{-}\right)\right]$at different collision energies.

\section{Conclusions}

The deprotonated 2-(4,6-dimethoxypyrimidin-2-ylsulfanyl)-N-phenylbenzamide and its derivatives were studied by negative-ion electrospray ionization tandem mass spectrometry, and the proposed fragmentation pathways were elucidated. These mechanisms were supported by the analysis of exact mass measurements and the analysis of N-cyclohexyl-2-(4,6-dimethoxypyrimidin-2-ylsulfanyl)benzamide. Theoretical calculations were also invoked to shed light on the reaction mechanisms of Compound 1 by the semiempirical PM3 method. All the compounds showed similar fragmentation pathways. Two competitive gas-phase Smiles rearrangement reactions were observed. For 2-(4,6dimethoxypyrimidin-2-ylsulfanyl)-N-phenylbenzamide derivatives, this reaction gave rise to $\left[\mathrm{M}-\mathrm{H}-\mathrm{C}_{7} \mathrm{H}_{4} \mathrm{OS}\right]^{-}$ and $\left[\mathrm{M}-\mathrm{H}-\mathrm{C}_{13} \mathrm{H}_{8} \mathrm{NSR}\right]^{-}$. The $\ln [(\mathrm{M}-\mathrm{H}-$ $\left.\left.\mathrm{C}_{7} \mathrm{H}_{4} \mathrm{OS}^{-}\right) /\left(\mathrm{M}-\mathrm{H}-\mathrm{C}_{13} \mathrm{H}_{8} \mathrm{NSR}^{-}\right)\right]$values of the parasubstituted compounds gave a linear relationship with the Hammett constant of the substituents. In addition, three methyl-substituted isomers were differentiated through the plots of $\ln \left[\left(244^{-}\right) /\left(155^{-}\right)\right]$versus collision energy since the relative abundances of the product ions were affected by the substitution position.

\section{Acknowledgments}

The authors gratefully acknowledge financial support from the National Natural Science Foundation (no. 20672098, 20375036) and the NSF of Zhejiang Province (no. Z206510).

\section{References}

1. Nezu, Y.; Miyazaki, M.; Sugiyama, K.; Kajiwara, I. Dimethoxypyrimidines as a Novel Herbicide. Part 1. Synthesis and Herbicidal Activity of Dimethoxyphenoxypyrimidines and Analogues. J. Pestic. Sci. 1996, 47, 103-113.

2. Nezu, Y.; Miyazaki, M.; Sugiyama, K.; Kajiwara, I. Dimethoxypyrimidines as a Novel Herbicide. Part 2. Synthesis and Herbicidal Activity of O-Pyrimidinylsalicylates and Analogues. J. Pestic. Sci. 1996, 47, 115-124.

3. Luthy, C.; Zondler, H.; Rapold, T.; Seifert, G.; Urwyler, B.; Heinis, T. Steinrucken, H. C.; Allen, J. 7-(4,6-Dimethoxypyrimidinyl)Oxy and Thiophthalides as Novel Herbicides: Part 1. CGA 279 233: A new Grass-Killer for Rice. Pest. Manag. Sci. 2001, 57, 205-224.

4. Nezu, Y.; Wada, N.; Saitoh, Y.; Takahashi, S.; Miyazawa, T. Synthesis and Herbicidal activity of Pyrimidinyl Salicylic and Thiosalicylic Acids. J. Pestic. Sci. 1996, 21, 293-303.

5. Wu, J.; Chen, M. F.; Wang, L. H.; Zhang, P. Z. 2-(4,6-Dimethoxypyrimidin2-Ylsulfanyl) -N-Phenylbenzamide. Acta Crystallogr. E 2005, E61, o3728-03729.

6. Busch, K. L.; Glish, G. L.; McLuckey, S. A. Mass Spectrometry/ Mass Spectrometry: Techniques and Applications of Tandem Mass Spectrometry. VCH Publishers: New York, 1988; p 53.

7. Lobodin, V. V.; Ovcharenko, V. V.; Pihlaja, K.; Morzherin, Y. Y.; Lebedev, A. T. "Tert-Amino Effect" Induced by Electron Ionization and Comparison with Thermal Reaction in Solution. Rapid Commun. Mass Spectrom. 2004, 18, 724-728.

8. Glish, G. L; Cooks, R. G. The Fischer Indole Synthesis and Pinacol Rearrangement in the Mass Spectrometer. J. Am. Chem. Soc. 1978, 100, $6720-6725$.

9. Wang, H. Y.; Zhang, X.; Guo, Y. L. Using Tandem Mass Spectrometry to Predict Chemical Transformations of 2-Pyrimidinyloxy-N-Arylbenzyl Amine Derivatives in Solution. J. Am. Soc. Mass Spectrom. 2006, 17, 253-263.

10. Lin, H. Y.; Ridge, D. P.; Uggerud, E.; Vulpius, T. Unimolecular Chemistry of Protonated Formamide. Mass Spectrometry and ab Initio Quantum Chemical Calculations. J. Am. Chem. Soc. 1994, 116, 2996-3004

11. Tu, Y. P.; Harrison, A. G. Fragmentation of Protonated Amides Through Intermediate Ion-Neutral Complexes: Neighboring Group Participation. J. Am. Soc. Mass Spectrom. 1998, 9, 454-462.

12. Warren, L. A.; Smiles, S. Iso- $\beta$-Naphthol Sulphide. J. Chem. Soc. 1930, 956.

13. Truce, W. E.; Kreider, E. M.; Brand, W. W. The Smiles and Related Rearrangements of Aromatic Systems. Org. React. 1970, 18, 99-215.

14. Eichinger, P. C. H.; Bowie, J. H.; Hayes, R. N. The Gas-Phase Smiles Rearrangement: A Heavy Atom Labeling Study. J. Am. Chem. Soc. 1989, $111,4224-4227$

15. Eichinger, P. C. H.; Bowie, J. H. The Gas-phase Smiles Rearrangement. The Effect of Ring Substitution. An ${ }^{18} \mathrm{O}$ Labelling Study. Org. Mass Spectrom. 1992, 27, 995-999.

16. Eichinger, P. C. H.; Dua, S.; Bowie, J. H. A Comparison of Skeletal Rearrangement Reactions of Even-Electron Anions in Solution and in the Gas Phase. Int. J. Mass Spectrom. Ion Processes 1994, 133, 1-12.

17. Wang, F. Collision-Induced Gas-Phase Smiles Rearrangement in PhenoxyN-Phenylacetamide Derivatives. Rapid Commun. Mass Spectrom. 2006, 20, $1820-1821$.

18. Hiserodt, R. D.; Pope, B. M.; Cossette, M.; Dewis, M. L. Proposed Mechanisms for the Fragmentation of Doubly Allylic Alkenamides (Tingle Compounds) by Low Energy Collisional Activation in a Triple Quadrupole Mass Spectrometer. I. Am. Soc. Mass Spectrom. 2004, 15, 1462-1470.

19. Filho, E. R.; Almeida, A. M. P.; Tabak, M. Fragmentation of Dipyridamole and Related Dipyrimidines by ESI-CAD Mass Spectrometry. J. Mass Spectrom. 2003, 38, 540-547.

20. Makowiecki, J.; Tolonen, A.; Uusitalo, J.; Jalonen, J. Cone Voltage and Collision Cell Collision-Induced Dissociation Study of Triphenylethylenes of Pharmaceutical Interest. Rapid Commun. Mass Spectrom. 2001, 15, 1506-1513.

22. Bowie, J. H. The Fragmentation of Even-Electron Organic Negative Ion. Mass Spectrom. Rev. 1990, 9, 349-379.

23. Smith, M. B. Organic Synthesis; McGraw-Hill: New York, 2002, pp $164-166$.

24. Hansch, C.; Leo, A.; Taft, R. W. A Survey of Hammett Substituent Constant and Resonance and Field Parameters. Chem. Rev. 1991, 91, 165-195. 